\title{
Diacronie
}

Studi di Storia Contemporanea

$\mathrm{N}^{\circ} 11,3$ | 2012

La satira fa storia. Eventi, pratiche, linguaggi

\section{Los barrios se ríen de la ciudad}

Las acciones satíricas del movimiento vecinal español. El caso de Valladolid, 1970-1986

\section{Constantino Gonzalo Morell}

\section{(2) OpenEdition}

Journals

\section{Edición electrónica}

URL: http://journals.openedition.org/diacronie/2672

DOI: 10.4000/diacronie. 2672

ISSN: 2038-0925

\section{Editor}

Association culturelle Diacronie

Referencia electrónica

Constantino Gonzalo Morell, « Los barrios se ríen de la ciudad », Diacronie [En línea], N 11, 3 | 2012, documento 6, Puesto en línea el 29 octubre 2012, consultado el 01 mayo 2019. URL : http:// journals.openedition.org/diacronie/2672 ; DOI : 10.4000/diacronie.2672 


\title{
Diacronie
}

6/

\section{Los barrios se ríen de la ciudad}

\section{Las acciones satíricas del movimiento vecinal español. El caso de Valladolid, 1970-1986}

\author{
Constantino Gonzalo MORELL*
}

Con el presente artículo tratamos de demostrar que un movimiento social urbano, como el movimiento asociativo vecinal, puede plantear sus reivindicaciones y denunciar graves carencias a partir del humor y la sátira. Para ello, tomaremos el ejemplo del de Valladolid, ciudad española de tamaño medio.

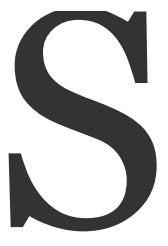

egún el más prestigioso científico social español, Manuel Castells, el movimiento vecinal de España es «el movimiento urbano más extendido y significativo en Europa desde $194{ }^{{ }^{1}}{ }^{\text {, }}$ lo que no ha supuesto el reconocimiento para el mismo más que en fechas recientes y de una forma limitada en la historiografía. Sin embargo, entre 1968 y 1977 se crearon más de mil asociaciones de vecinos en todo el país ${ }^{2}$, con más de un millón de socios y 3500 locales. Unas cifras astronómicas para cualquier movimiento social en España, viejo o nuevo, muy superiores a las de cualquier partido de ámbito estatal y que sólo una institución como la Iglesia puede superar, puesto que Iglesia y asociaciones de vecinos son las únicas entidades que están presentes en todos los barrios del país.

Mientras que obreros, estudiantes y miembros del clero son reconocidos unánimemente como referentes de la lucha contra la dictadura, este reconocimiento se está haciendo extensivo al mundo vecinal sólo en los últimos tiempos. Pero si la lucha de los primeros puede ser catalogada de directa, con duros enfrentamientos con los pilares del régimen - lo que no significa ni mucho menos que siempre fuera así-, las

\footnotetext{
${ }^{1}$ CASTELLS, Manuel, La ciudad y las masas. Sociología de los movimientos sociales urbanos, Madrid, Alianza, 1986, p. 299.

${ }^{2}$ Treinta aniversario Asociaciones de Vecinos, Valencia, CAVE, 1998, p. 2.
} 
luchas vecinales, la mayor parte de las veces han respondido a otros modos, que hoy podríamos catalogar como blandos, respondiendo plenamente a su adscripción dentro de los denominados Nuevos Movimientos Sociales, en los que el humor y la sátira casi siempre estarán presentes. Frente a los modos directos de obreros y estudiantes, huelgas y manifestaciones, los vecinos desplegarán también nuevas tácticas para socavar los apoyos del franquismo y concitar el apoyo de la opinión pública en torno a sus causas de barrio.

\section{1. ¿Qué es una asociación de vecinos?}

El movimiento asociativo vecinal español no es el único movimiento urbano que ha existido. Incluso en otros países hay organizaciones que comparten alguna característica con él. En Francia aparecerán en los sesenta los GAM (Groupes d'Action Municipaux), en Italia los Comitati di quartierie, en Portugal las Comissões de moradores, etc.; en Iberoamérica, los ocupantes de México o en el Chile de 1967 a 1973 - fechas parejas a las españolas - las Juntas de Vecinos democristianas y los Comandos Comunales por parte de la izquierda ${ }^{3}$. Sin embargo, no hay parangón con las asociaciones de vecinos españolas, puesto que partidos y sindicatos asumieron desde el principio muchas reivindicaciones urbanas - directamente o a través de organizaciones creadas ad hoc - y en segundo lugar, porque las Administraciones locales han sido más eficientes y representativas que las españolas, así como más sensibles a las demandas sociales ${ }^{4}$.

Como defiende Javier Angulo, si analizamos movimientos sociales urbanos foráneos, llegamos a la conclusión de que nuestras asociaciones son únicas, porque en ningún otro Estado una organización ha reunido las características del movimiento vecinal español; pues o son puramente marginales o están plenamente integradas en el aparato del Estado ${ }^{5}$, siendo una de las características tanto en sus orígenes como en la actualidad su posición anti-institucional o al menos no institucional ${ }^{6}$, algo que es bastante lógico si la mayor parte de sus reivindicaciones son contra o para las Administraciones.

\footnotetext{
3 BORJA, Jordi, Por unos municipios democráticos. Diez años de reflexión política y movimiento ciudadano, Madrid, Instituto de estudios de Administración local, 1986, p. 40.

${ }^{4}$ Ibidem, p. 41.

5 ANGULO URIBARRI, Javier, Municipio, elecciones y vecinos. Por unos Ayuntamientos democráticos, Madrid, Ediciones de La Torre, 1978, p. 156.

${ }^{6}$ IBARRA, Pedro, TEJERINA, Benjamín, Los movimientos sociales. Transformaciones políticas y cambio cultural, Madrid, Editorial Trotta, 1988, p. 12.
} 
Lo que hoy entendemos por asociaciones de vecinos, tiene una fecha de origen muy clara: el año 1964. El 24 de diciembre de 1964 se sanciona la Ley de Asociaciones 191/64, que regula y estipula la aparición de Asociaciones de Cabezas de Familia ${ }^{7}$, primera forma de movimiento social urbano en España, en el marco del Movimiento Nacional. Probablemente sea Javier Berriatua, desde el ámbito del derecho, quien más se haya preocupado por definir teóricamente qué es una AVV. Para él una Asociación de Vecinos es un movimiento social urbano, autónomo, permanente y legal. Es «la Asociación inframunicipal que tiene por objeto la defensa de intereses vecinales», cuyo elemento personal son los propios vecinos, su ámbito de actuación «una unidad vecinal inframunicipal» - el barrio - y su fin social «la defensa de intereses vecinales» ${ }^{8}$.

\section{El caso de Valladolid: los años '7o}

Hacia 1967, la primera ciudad de España era Madrid, con casi tres millones de habitantes, siendo Valladolid la $13^{\mathrm{a}}$ población más importante del país, con 203.011. La ciudad del Pisuerga debe gran parte de su crecimiento al ferrocarril. Su estratégica posición geoespacial la sitúa en medio de la vital línea Madrid-Irún, siendo, hasta la llegada de la empresa Renault en la década de los cincuenta, la principal industria local, ocupando a más trabajadores directos ${ }^{9}$.

A la posición estratégica de la ciudad y su peso demográfico hay que sumar la presencia de una de las universidades más antiguas de España, que podía suministrar cuadros técnicos. Hasta mediados del pasado siglo, el crecimiento de la ciudad, como afirma Alfonso Álvarez, no se diferenció del de otras ciudades españolas del mismo período $^{10}$. Es una decisión política la que cambie esta situación y es la elección de la capital del Pisuerga como Polo de Desarrollo, el 30 de enero de 1964 (con vigencia hasta el 31 de diciembre de 1970). La concesión por parte del II Plan de Desarrollo Económico y Social de esta condición - recordemos que existen otras diez ciudades en toda España - se explica por varias circunstancias: la existencia de mano de obra abundante y meridianamente cualificada, la experiencia en las fábricas ferroviarias, la presencia de una infraestructura educativa conveniente para la formación técnica de los

\footnotetext{
${ }^{7}$ Pues Familia, Religión y Ejército serán los tres pilares más importantes para la dictadura franquista.

${ }^{8}$ BERRIATUA SAN SEBASTIÁN, Javier María, Las asociaciones de vecinos, Madrid, Instituto de Estudios de Administración Local, 1977, pp. 66 y 142.

9 ÁlVAREZ MORA, Alfonso, La construcción histórica de Valladolid. Proyecto de ciudad y lógica de clase, Valladolid, Universidad de Valladolid, 2005.

${ }^{10}$ Ibidem, p. 149.
} 
nuevos trabajadores y la ubicación de la ciudad, a medio camino entre la capital del país y la poderosa industria del norte ${ }^{11}$.

El Polo de Desarrollo vallisoletano será el único que supere las expectativas del II Plan de Desarrollo, siendo las inversiones un 68,1\% más de las previstas y generando un 80\% más de empleo del proyectado. De 1964 a 1970 se cifran en 1418 los puestos de trabajo anuales creados por las distintas fábricas, aumentando en el breve período 1971-74 a 2064, lo que convierte a nuestra ciudad en un núcleo de absorción de mano de obra ${ }^{12}$.

La población de Valladolid en 1960 es de 151.807 habitantes. Veinte años más tarde asciende a 330.242, lo que supone un crecimiento del 117,5\%, convirtiéndose en uno de los centros urbanos españoles con mayor capacidad de crecimiento del período.

El extraordinario crecimiento demográfico de la urbe vino acompañado, lógicamente, de un crecimiento material de la propia ciudad. Para Alfonso Álvarez el problema general de la vivienda en España se agrava en las ciudades de tamaño medio, no tanto por sus cifras, pues afecta a un número mucho mayor de personas y de una forma más grave cuanto más importante sea la aglomeración urbana, como por la imposibilidad de su resolución. Esta ausencia de mecanismos confirió a los procesos de ocupación residencial tintes marginales, apareciendo soluciones como las que se dieron en Valladolid ${ }^{13}$, a base de barrios aislados y alejados del núcleo de la ciudad, en forma de aureola. Al fin y al cabo, había que dar cobijo, fuera de la forma que fuera, a esa nueva masa obrera que alimentaba las fábricas del desarrollismo franquista.

\section{El movimiento vecinal de la ciudad}

El movimiento vecinal español, para Alice Gail, supone la solución a la incapacidad de las Corporaciones municipales de responder a las necesidades de servicios generadas por el crecimiento urbano y estuvo condicionado por los factores propios de cada barriada y ciudad, de modo y manera que a una urbe de industrialización e inmigración moderada le cabían más posibilidades de planificar su crecimiento frente a otra de parámetros más acelerados ${ }^{14}$, como es el caso de Valladolid. Además, por su

\footnotetext{
${ }^{11}$ GARCÍA FERNÁNDEZ, Jesús, Crecimiento y estructura urbana de Valladolid, Barcelona, Los Libros De La Frontera, 1974, p. 35.

${ }^{12}$ PASTOR, Luis Jesús, PASCUAL, Henar, Conocer el barrio de Los Pajarillos. Una compleja periferia obrera de la ciudad de Valladolid, Valladolid, Ayuntamiento de Valladolid, 1994, p. 30.

${ }_{13}$ ÁLVAREZ MORA, Alfonso, op. cit., p. 150.

${ }^{14}$ GAIL BIER, Alice, Crecimiento urbano y participación vecinal, Madrid, CSIC, 1980, p. 15.
} 
carácter reivindicativo, se hizo muy difícil saber, incluso para las autoridades, hasta qué punto las protestas vecinales eran por carencias y hasta cuál oposición al régimen ${ }^{15}$.

$\mathrm{Su}$ nacimiento a finales de la dictadura le dará al movimiento vecinal un carácter «progresista, su visión integral de los problemas de las barriadas, y una defensa de los intereses colectivos por encima de los individuales o de grupos concretos, además de un vínculo importante, desde su nacimiento, con otros movimientos sociales» ${ }^{16}$. Partiendo de las necesidades más básicas, desde el alcantarillado a la iluminación, pasando por las plazas escolares o la higiene, los vecinos de los barrios de Valladolid creaban una nueva cultura política, donde la participación y el intercambio de ideas eran las grandes claves. Una nueva dinámica que forzó a los últimos representantes municipales del Franquismo, primero, y a los democráticos después, a responder a las demandas de los barrios. Unas demandas que quizá supusieron una nueva sensibilidad de las administraciones hacia las olvidadas barriadas. Como recuerda Feliciano Escudero para su barrio de Belén, «la Asociación de Vecinos [de Belén] ha forzado la mayor parte de las mejoras que se han conseguido en el barrio. Todo ha sido a base de luchar y reivindicar... Nada ha sido gratis. Todo a fuerza de presionar y movilizarse, y muchas horas en los despachos de los Concejales» ${ }^{17}$. Unos cambios y mejoras que son extensibles a todas las asociaciones y barriadas de la ciudad.

La aparición de un nuevo actor como fue el movimiento ciudadano, forzó a los Ayuntamientos a dedicar sus fuerzas y sus recursos también a los hasta entonces olvidados barrios. Cabría destacar la valoración global sobre la aportación del movimiento vecinal a la ciudad, realizada por el ex alcalde (1979-1995) Tomás Rodríguez Bolaños:

el de Valladolid yo creo que de los mejores de España, lo digo sinceramente. Fue un movimiento que estaba muy organizado, fue un movimiento que tenía las cosas muy claras, que no solamente se ocupaba de los problemas propios de su barrio sino de una articulación de la sociedad. Fue un movimiento que se preocupó de la democratización de este país, en Valladolid, pero también con repercusiones fuera

\footnotetext{
${ }^{15}$ GARCÍA-NIETO PARÍS, María Carmen, «Marginalidad, movimientos sociales, oposición al franquismo. Palomeras, un barrio obrero de Madrid, 1950-1980", in TUSELL, Javier, ALTED, Alicia, MATEOS, Abdón (Coords.), La oposición al régimen de Franco. Estado de la cuestión y metodología de la investigación, Tomo II, Madrid, UNED, 1990, pp. 278, 279.

${ }^{16}$ FERNÁNDEZ, Eva, «Qué representó en los inicios de la democracia el movimiento asociativo vecinal y qué representará en el siglo XXI», in Revista D'estudis de la Violència, 4/2008, p. 3.

${ }^{17}$ ESCUDERO, Feliciano, «Toda una vida al servicio del Barrio Belén», in Nodo 50 [on-line], URL: < www.nodo5o.org >, [consultado 15 de marzo 2009].
} 
de Valladolid, y fue un movimiento, al frente hubo gente importante y hubo gente importante que ha hecho mucho en Valladolid y fuera de Valladolid ${ }^{18}$.

\section{La sátira vecinal}

De 1970, en que aparece la primera asociación de vecinos vallisoletana en forma de Asociación de Cabezas de Familia amparándose en la Ley de Asociaciones de 1964, a 1986, serán cientos las acciones protagonizadas por las asociaciones de la ciudad, reivindicando servicios, luchando por los barrios, creando en definitiva un concepto nuevo de ciudad y de relaciones urbanas. Aún siendo las protestas clásicas (recogida de firmas, escritos, manifestaciones, etc.) las más habituales, no menos cierto es que éstas estuvieron acompañadas de otras acciones, paralelas o no, mucho más originales y humorísticas.

La primera que vamos a tratar no está protagonizada por el movimiento vecinal como tal, pero al serlo por un personaje tan afín como vital para él, creemos merece un espacio en este artículo. Nos referimos al entonces párroco de La Pilarica, el jesuita Buenaventura Alonso, uno de los referentes claves en la oposición a la dictadura en la ciudad y promotor directo de las asociaciones de vecinos de su barrio, Pilarica, y el del anejo de Belén. La barriada de La Pilarica, como la gran mayoría de los nuevos barrios surgidos al otro lado de la vía, crecido entre las huertas reconvertidas en terrenos urbanos para acoger el aluvión de obreros fabriles, contaba con unas infraestructuras muy precarias, con calles de tierra apisonada, sufriendo por ello las incomodidades climatológicas en forma de baches, barro y polvo. Según cuenta el propio Alonso en un texto que dejó en los años noventa a modo de memorias incompletas y aprovechando la presencia del primer edil en el barrio para presidir la procesión de la Virgen del Pilar (obvia patrona del barrio), el 12 de octubre:

aquel año estuvo lloviendo hasta poco antes de empezar la procesión. Previendo el asunto, me calé unas botas un tanto viejas pero resistentes al agua. De esa forma recibí al Sr. Alcalde, D. Antolín de Santiago y Juárez, que no quiso perderse su presencia en el barrio. Arrancó la procesión y yo iba junto al Sr. Alcalde haciendo breves comentarios. Haciéndome el distraído, me metía a derecho en los profundos charcos de agua. D. Antolín, por no ser menos, metía sus brillantes zapatos por

\footnotetext{
${ }^{18}$ GONZALO MORELL, Constantino, Entrevista a Tomás Rodríguez Bolaños, Valladolid, 23 de noviembre de 2009 [entrevista realizada por el autor del ensayo].
} 
idéntico sitio... Poco tiempo después las calles fueron asfaltadas por orden del Excelentísimo Ayuntamiento... ${ }^{19}$.

La utilización de un evento religioso para organizar una protesta es un punto de encuentro común en la España del "Nacionalcatolicismo", donde autoridades y clero siempre van de la mano. Por eso no es extraño que en la vecina ciudad de Palencia y ya en 1976 se aprovechara una romería para efectuar una protesta ante las autoridades. Es en la barriada del Cristo del Otero (presidido por un cerro con una representación escultórica de Cristo), donde cada domingo más próximo al 16 de abril los palentinos rememoran el apedreamiento y posterior petición de perdón a Santo Toribio con una "pedrea" de quesos y panes por parte de las autoridades. Como relata el líder vecinal palentino Abel Alonso:

con motivo de aquello se hizo una acción que consistía en grandes pancartas en la imagen del Cristo del Otero, [...] una serie de cosas reivindicando... luz, aceras, alcantarillado, pues toda una serie de estructuras del que el barrio carecía entonces. [...] hubo una protesta que se devolvió cuando tiraron las autoridades el pan y el queso, los vecinos devolvían el pan y el queso al alcalde, que fue una pedrea un tanto a la inversa, de la más insólita que ha habido. Ahí arrancó esa asociación y a partir de ahí el resto de barrios fueron tomando conciencia y de alguna manera se fue encendiendo... ${ }^{20}$.

Una escena curiosa e impagable de ver donde alcalde y concejales se vieron sorprendidos por el rechazo popular y la devolución de los presentes alimenticios a las autoridades municipales. Forma más que gráfica e irónica del descontento del barrio por su situación de abandono.

Poco tiempo después y volviendo a Valladolid, son los vecinos de la Rondilla los que protagonizan una acción satírica, cuando cogiendo sus propias escobas, ponen en evidencia la falta de limpieza del barrio por parte del Ayuntamiento. El 18 de julio de $1976^{21}$ la asociación convocó a su primera acción - fuera del marco de la campaña sobre la constructora Imperial, de la que hablaremos más adelante - a los vecinos de la Rondilla a que «pertrechados de una escoba, sustituyesen las obligaciones del

\footnotetext{
${ }^{19}$ Archivo de la Asociación Vecinal Rondilla (AAVR), Mis experiencias como párroco de La Pilarica, texto autobiográfico de Buenaventura Alonso, Valladolid, [¿̇Años 90?].

${ }^{20}$ GONZALO MORELL, Constantino, Entrevista a Abel Alonso, Valencia, 15 de diciembre de 2008 [entrevista realizada por el autor del ensayo].

${ }^{21}$ «aunque yo personalmente, soy partícipe en la organización pero se decidió que fuera un 18 de Julio, "que tiene bemoles"». Puesto que recordemos que hasta 1978, el 18 de julio era Fiesta Nacional, remarcando lo de Nacional, pues conmemoraba la insurrección que terminó con la legítima y democrática opción republicana en España. GONZALO MORELL, Constantino, Entrevista a Ángel Ceballos, Valladolid, 3 de diciembre de 2008 [entrevista realizada por el autor del ensayo].
} 
Ayuntamiento realizando "la gran barrida" ${ }^{22}$. De este modo, unas cuarenta personas se reunieron la mañana de ese domingo de julio, escoba y bolsa en ristre. Después se concentraron en el descampado contiguo al colegio "Gutiérrez del Castillo", donde llevaron a cabo una asamblea «en la que se puso de manifiesto que, a pesar de que por la noche del día anterior los servicios de limpieza se habían esforzado por limpiar en lo posible todo el barrio; la realidad era que el barrio seguía teniendo basura, aunque en una cuantía sensiblemente inferior». Concluida la asamblea, decidieron manifestarse por el barrio, llevando consigo algunas de las bolsas de basura recogida. La manifestación se disuelve pacíficamente, tras la conminación de la Policía a que depusieran su actitud ${ }^{23}$.

Si bien es cierto que el Ayuntamiento de Valladolid, como todos los del país, no contaba con recursos suficientes para hacer frente a todas las necesidades de sus ciudadanos - recordemos que hasta los años '8o no aparecen las leyes para financiar al régimen local, leyes precarias como se está comprobando actualmente - no menos cierto es que los pocos recursos existentes se empleaban asiduamente en el centro de la ciudad, aun cuando todos los habitantes, independientemente de donde vivieran, pagaran las preceptivas tasas de limpieza. De este modo, mientras que la zona centro se limpiaba todos los días, esa misma limpieza llegaba con suerte en días alternos a los barrios... cuando llegaba. Precariedad en la limpieza, pero también en la iluminación. Ante la falta de alumbrado público, la asociación de vecinos de San Pedro convoca una manifestación con velas. Velas como símbolo de la falta de luz (es el recurso que hay en muchas casas ante un eventual apagón) pero también con el doble sentido, por la expresión española de "estar a dos velas", por la falta de dinero. Así, «unas cincuenta personas se manifestaron por las principales calles del barrio de San Pedro Regalado portando velas como protesta por la falta de alumbrado» ${ }^{24}$. Otro frente vecinal será el urbanístico, concretado en este caso en el problema de las casas edificadas por la Constructora Imperial SL (la Imperial) en el barrio de Rondilla.

Las lentas acciones legales iniciadas por los representantes de los afectados crean divergencias entre los mismos sobre las posibles soluciones, pues se desconfía de la Justicia tardofranquista tanto como de las autoridades que permitieron que un constructor sin escrúpulos se enriqueciera a base de vender casas de protección oficial

22 CASTRILLO ROMÓN, María, SANTOS GANGES, Luis, «Urbanisme et militantisme de quartier dans les quartiers populaires de Valladolid», in Espaces et sociétés, 134, 3/2008, (el paginado se refiere al borrador en castellano consultado) p. 7 .

${ }_{23}$ «Tal y como prometieron. Los vecinos del barrio de la Rondilla de Santa Teresa limpiaron las basuras de las calles», in Diario Regional, Valladolid, 20 de julio de 1976, p. 10.

${ }^{24}$ «Velas contra la falta de luz en San Pedro Regalado», in Libertad. Diario de la tarde, Valladolid, Prensa Nacional del Movimiento, 5 de diciembre de 1977, p. 7. 
ahorrándose partidas necesarias para su mantenimiento, como en los desagües. Esto explica la escalada de acciones llevada a cabo por o con el apoyo de la Asociación Familiar Rondilla: la necesidad de mantenerse unidos en la reclamación de justicia, no firmando un acuerdo extrajudicial que supondría unas reparaciones superficiales y sin consecuencias penales para los constructores. Semanas después de iniciado un juicio especial, lo que explica la importancia dada al caso que afectaba a cientos de familias y que supuso la atención informativa de toda la ciudad, se lleva a cabo la interpretación de una obra de teatro reivindicativa, que Libertad reflejaba de la siguiente forma:

\begin{abstract}
Alrededor de doscientas personas asistieron a la representación de un juicio imaginario contra el responsable de la construcción de las viviendas de La Rondilla. La representación, que tuvo lugar a las ocho y media, en una calle contigua a la parroquia, puso de manifiesto una vez más la inquietud existente entre los vecinos. La representación comenzó con la explicación del caso por un joven, que después habría de interpretar el papel de constructor, y seguidamente se inició el imaginario juicio, con fiscal, juez, abogado defensor, procesado, secretario del tribunal y funcionario. El "juicio" tuvo como resultado el declarar culpable al constructor de las viviendas ${ }^{25}$.
\end{abstract}

La obra en cuestión, redactada posiblemente por algún miembro de la asociación, donde se conserva un ejemplar, tenía como único título "Farsa a la empresa Imperial", siendo una obrilla de 5 folios, con 8 personajes, representando un fingido juicio. Una sátira con personajes tan significativos como el juez, el propio barrio de la Rondilla personificado, el ladrón o el lameculos, esbirro del constructor. La farsa, bebiendo de las experiencias del teatro popular, termina con el veredicto a muerte en la hoguera con exposición pública del cadáver del responsable de las penurias del barrio. Semanas después y pese a la publicación de la primera sentencia, favorable a los afectados, la campaña continúa, primero en forma de recital de canción protesta:

Parece que la canción se está convirtiendo en instrumento habitual de información, concienciación y expresión en algunos de nuestros barrios. El último día, informábamos a nuestros lectores de un acto celebrado el sábado en Pilarica en el que los vecinos plasmaron en canción los problemas del barrio y las críticas a la Administración [del que no hemos obtenido más información]. Pues bien, algo parecido ocurrió el domingo en Rondilla. Tema, el problema de las viviendas de La Imperial, que tanto preocupa en el barrio. Lugar, un improvisado escenario junto a la iglesia de Santa Teresa; protagonistas principales, un grupo de vecinos que, con guitarras, imaginación y buen humor, «montaron un número musical» que atrajo

\footnotetext{
25 «Representación teatral de un problema», in Libertad. Diario de la tarde, Valladolid, Prensa Nacional del Movimiento, 15 de abril de 1977, p. 6.
} 
la asistencia de numerosos vecinos del barrio. Alrededor de unas doscientas personas estuvieron presentes en el acto $^{26}$.

Las canciones interpretadas en esta especie de recital reivindicativo eran adaptaciones de canciones del momento o canciones populares, a las que se le había cambiado la letra por otra ad hoc. Destacamos la siguiente:

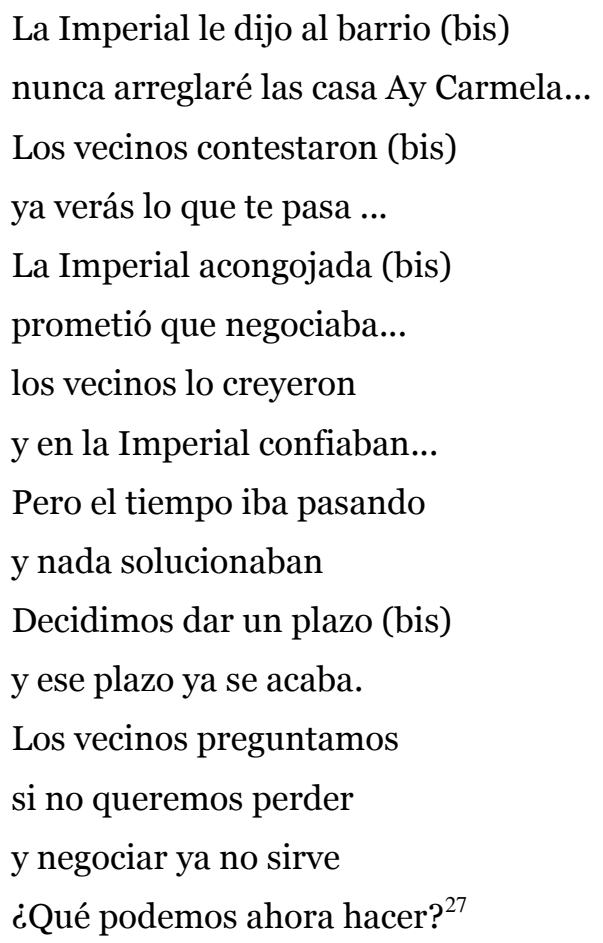

Germán Fandiño Pérez, en su estudio sobre el logroñés barrio de Yagüe ${ }^{28}$, encontró para fechas anteriores otra versión sobre la pavimentación de las calles del barrio. Teniendo en cuenta que creemos más que improbable que hubiera contactos entre el barrio riojano y el de la Rondilla, la explicación más lógica es que ambas asociaciones de vecinos hicieran sus respectivas versiones del mítico iAy, Carmela! de forma independiente y espontánea ${ }^{29}$. La segunda interpretación de la obra teatral Farsa a la empresa Imperial será suspendida por orden gubernativa ${ }^{30}$, lo que provocó un airado

\footnotetext{
${ }^{26}$ «Canciones para una asamblea», in Diario Regional, Valladolid, 21 de junio de 1977.

${ }^{27}$ AAVR, «El ejército del Ebro».

${ }^{28}$ FANDIÑO PÉREZ, Roberto Germán, Historia del movimiento ciudadano e historia local: el ejemplo del barrio de Yagüe en Logroño (1948-1975), Logroño, Instituto de Estudios Riojanos, 2003 , p. 108.

${ }^{29}$ Siendo su autoría más que incierta, con un pasado que algunos datan en la propia Guerra de Independencia y otros en el conflicto colonial marroquí, como toda canción popular conoció múltiples versiones, adaptadas a las circunstancias y a quienes la interpretaban, siendo una de ellas la que tiene como estrofa la frase: "prometemos resistir".

${ }^{30}$ "Cuando a las 19:45 un grupo de vecinos del barrio, pretendía ofrecer a sus convecinos una obra de teatro, en la que se denuncia el problema de las casas de la Imperial, [...], las fuerzas de orden público se presentaron en el lugar prohibiendo la celebración del citado acto.
} 
comentario en «Diario Regional» ${ }^{31}$ y demostró que no hay ningún resquicio posible para las autoridades si lo que se pretende es cuestionar al sistema, por mucho que sea con una inocente obra de teatro.

El intento de representación patentiza finalmente la división en dos bloques de los vecinos de las viviendas afectadas. Por un lado la comisión de afectados, que representa a la mayoría de los propietarios y que durante meses ha seguido la vía legal. Por el otro, el grupo de vecinos que considera que ese sistema es demasiado lento para unas casas con tan graves problemas estructurales y «con un final donde la "sorpresa" no está descartada. Para ellos, la unión del barrio, y su presión directa, es la única vía para una solución positiva a los vecinos». La comisión de afectados, cansada de las iniciativas vecinales hace pública la siguiente nota: «esta comisión y los afectados por el problema, ninguna relación tienen con la citada actividad o actuación [teatral], teniendo además que añadir, que desaprueban totalmente la actitud y manifestaciones de estos vecinos del barrio, que ni siquiera están afectados por este asunto, que perturban la buena gestión de los verdaderamente enterados, entrometiéndose en un problema cuya solución únicamente compete a los Tribunales de Justicia» ${ }^{32}$.

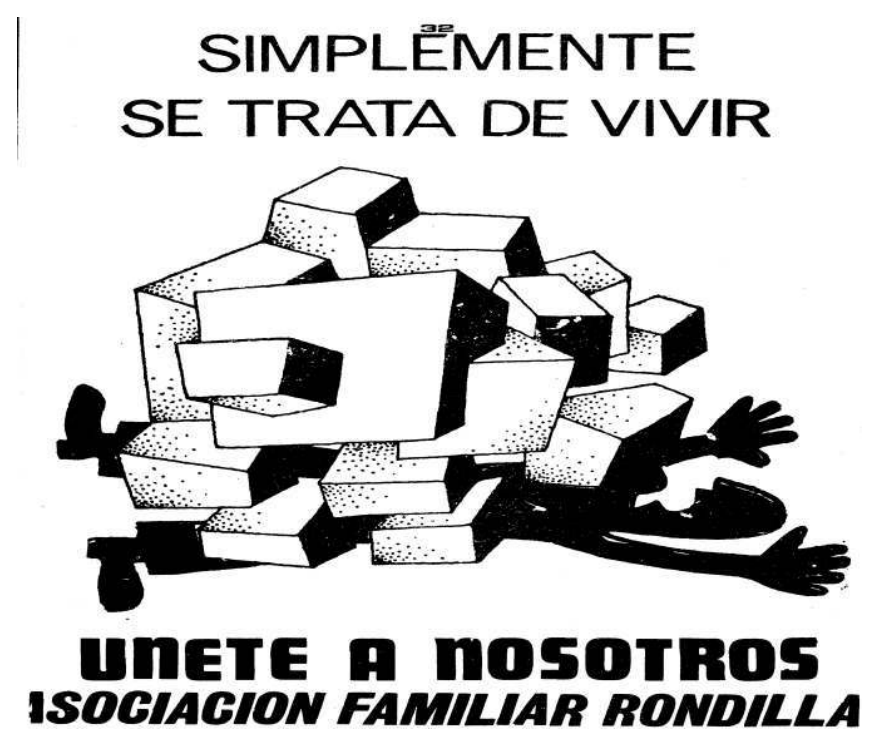

Caricatura sobre la densificación del barrio de la Rondilla, dibujo probablemente realizado por el artista Manuel Sierra.

Consideramos que esta actuación, va en contra de los intereses de la clase trabajadora, de la solución de sus problemas y nos demuestra que la libertad y la democracia no es una realidad en nuestro país, sino palabras manejadas con las que nos están engañando». Cfr., «Comunicado de un grupo de vecinos de Rondilla», in Diario Regional, Valladolid, 24 de junio de 1977, p. 9.

${ }^{31}$ GARCÍA, Ramón, «El teatro popular de la Rondilla», in Diario Regional, Valladolid, 27 de junio de 1977.

32 «Vecinos de la Rondilla contra las "representaciones" teatrales», in Diario Regional, Valladolid, 26 de junio de 1977. 
Otro problema urbanístico grave de los barrios es la falta de zonas verdes y servicios, porque los promotores inmobiliarios no construyen parques ni dejan espacio para colegios en las barriadas obreras. Sólo en las promociones destinadas a clases más pudientes se contemplarán estos servicios.

Y ello pese a la obligatoriedad legal de zonas verdes y servicios por cada zona edificada.

En 1978 y con la oposición a los diversos Planes Parciales que las últimas autoridades impuestas por el franquismo quieren aprobar, se desarrollan una serie de tensos plenos en el Ayuntamiento vallisoletano, donde las asociaciones de vecinos de la ciudad mostraron su descontento. De esta forma, cuando los ediles trataron el tema del «Plan Parcial Ribera de Castilla», que declaraba edificable el único terreno donde el barrio podía obtener los servicios tantas veces negados (parque, ambulatorio, residencia de tercera edad, colegios, instituto, etc.): «al darse el visto bueno a un plan y escucharse las corroboraciones de los capitulares - se aprueba, se aprueba - se escuchó en la tribuna un "beee" que provocó en la tribuna carcajadas»" ${ }^{33}$. Obsta decir que los vecinos, tras soltar una pancarta y gritar pidiendo la dimisión del alcalde, fueron expulsados del edificio. Poco después el pleno municipal vuelve a ser objeto del boicot del movimiento vecinal, con una sátira de las decisiones municipales, llevando a cabo un pleno paralelo que describe así el diario falangista "Libertad":

\begin{abstract}
A la finalización del Pleno de la Corporación Municipal celebrado esta mañana en el Ayuntamiento, e inmediatamente después de que el alcalde señor Vidal hiciera sonar su campanilla para levantar la sesión, se escuchó otra campanilla en el salón de sesiones y la voz de «se abre la sesión». [...] la voz del público que abría la sesión prosiguió: «[...] ante las contínuas agresiones de todo tipo que desde la Corporación Municipal somos objeto los barrios de la Ciudad de Valladolid, sus vecinos, conscientes de la gravedad de la situación, que hipoteca por muchos años el futuro de la ciudad, nos constituímos en Consejo abierto y sometemos a debate público el siguiente orden del día: Solares para edificaciones escolares, planes parciales y estudio de detalle, exacciones, tasas e impuestos municipales... Y en este instante, miembros de la Policía Municipal no dejaron proseguir con la lectura del orden del día, haciendo que se desalojara la tribuna pública» ${ }^{34}$.
\end{abstract}

\footnotetext{
33 «Incidentes durante el Pleno. Vecinos de la Rondilla, desalojados de la tribuna pública», in $E l$ Norte de Castilla, Valladolid, 1 de junio de 1978, p. 7.

${ }^{34}$ «Tras el Pleno Municipal de esta mañana. Las Asociaciones de Vecinos intentaron celebrar un Consejo Abierto", in Libertad, Valladolid, Medios de Comunicación Social del Estado, 30 de noviembre de 1978, p. 3.
} 
Ya para 1982, el líder vecinal de Pajarillos José Miguel Gutiérrez, recuerda como anécdota un corte de carretera reclamando un parque para el barrio, con «30 chavales y 25 adultos con ramas de árbol cortando Circunvalación [actual Paseo Juan Carlos I]», que al coincidir casualmente con el primer aniversario de la intentona golpista del 23-F, la Delegación del Gobierno interpretó como una concentración de extrema derecha. Un equívoco que se resuelve al llegar a la zona los antidisturbios y encontrar a los vecinos con ramas de árbol ${ }^{35}$. Esta misma asociación de Pajarillos, como también la de Rondilla, emplearon en sus campañas reclamando zonas verdes supuestos árboles de cartón o de madera, colocados en zonas estratégicas del barrio a modo de llamativos reclamos o directamente en las parcelas que se exigían como parques ${ }^{36}$.

Una forma tradicional de ridiculizar a las autoridades, típicamente mediterránea, son los carnavales. De cara al movimiento vecinal vallisoletano destacamos los carnavales, siempre reivindicativos para con las necesidades de los barrios de la Plataforma PIBEL (barrios de PIlarica y de BELén). Una función lúdico-festiva que tuvo su cénit cuando parodiaron los fastos oficiales en torno al 92 y el Quinto Centenario del Descubrimiento de América, cuando botaron en la Esgueva (segundo río en importancia de la ciudad), una réplica en poliestireno expandido de la nao Santa María. Este mismo sentido reivindicativo y lúdico tendrá la Cabalgata de Reyes organizada por la asociación del Barrio Girón en 1983, que fue confrontada por los medios de comunicación con la cabalgata oficial del Ayuntamiento como «cabalgata rica, cabalgata pobre» ${ }^{37}$.

\footnotetext{
${ }^{35}$ GONZALO MORELL, Constantino, Entrevista a José Miguel Gutiérrez de Diego, Valladolid, 12 de marzo de 2008. [entrevista realizada por el autor del ensayo].

36 «Cinco mil folletos informativos, ochocientos carteles y varios árboles de madera colocados por la Asociación Familiar de la Rondilla en diversas esquinas del barrio anunciarán, junto con la pintada realizada en la mañana de ayer, la exposición que se abrirá el próximo viernes día 13». Cfr., BALLESTERO, Javier, «La Rondilla comienza a palpar su gran parque en la Ribera de Castilla», in El Norte de Castilla, Valladolid, 3 de diciembre de 1985, p. 13.

${ }^{37}$ ASOCIACIÓN DE VECINOS VALLE DE OLID, 1975-1995. 20 años Barrio Girón Valladolid, Valladolid, Asociación de Vecinos Valle de Olid, 1995, p. 23.
} 


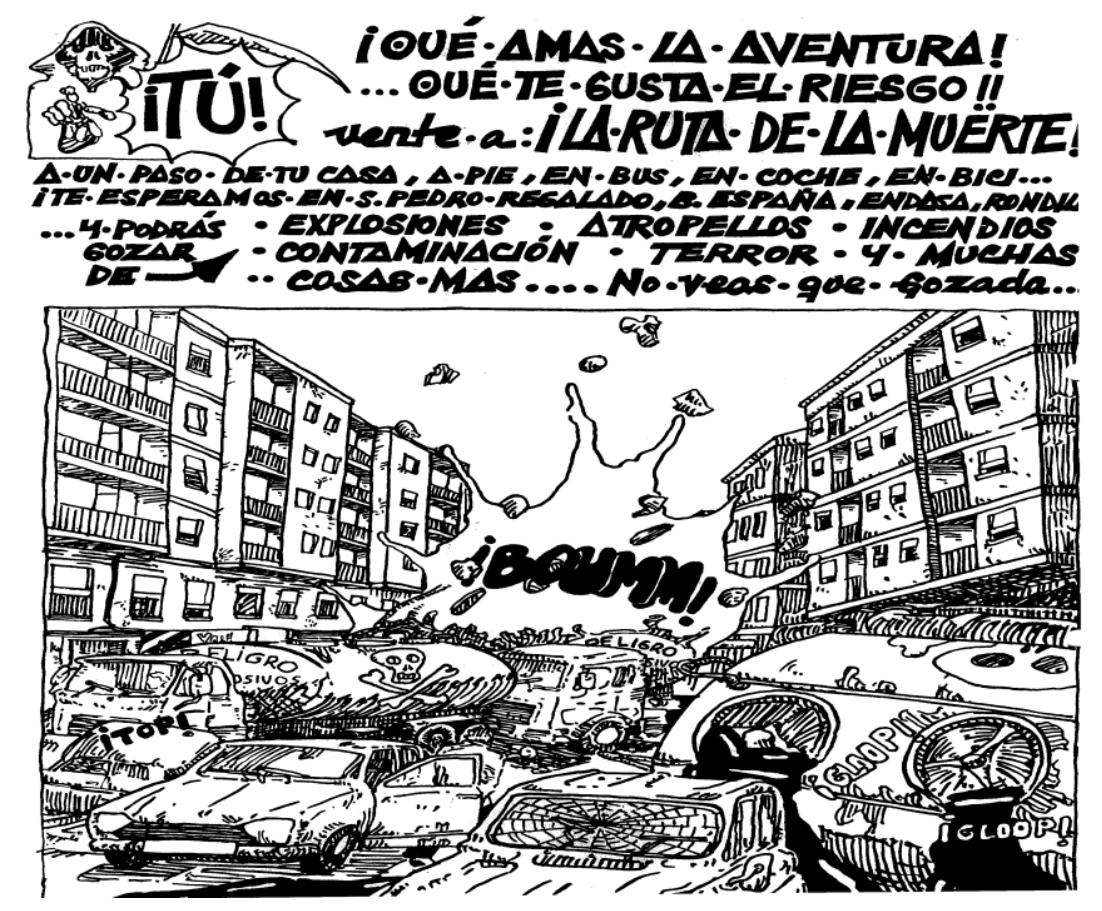

Dibujo irónico mostrando los peligros que viven los barrios de la ciudad por la ruta que llevan a cabo los camiones de combustible de CAMPSA por la ciudad

Por último y cerrando el ciclo que comenzamos en Pilarica, vamos a hablar de una parodia celebrada en este barrio. Si la primera a la que aludimos tuvo como protagonistas al párroco del barrio y al alcalde franquista, en 1985 serán la asociación de vecinos y el Ayuntamiento socialista. Prueba inequívoca de que la urbanización de los barrios fue un proceso lento y que supuso un trabajo reivindicativo duro y constante al movimiento vecinal es que, comenzada la adecuación de las principales calles de Pilarica a fines de los años sesenta, este proceso, a mediados de los ochenta, aún no había terminado. Por ello, por la sensación de abandono, por la lentitud de las obras y como protesta, la asociación realizó una parodia de inauguración de calles por el barrio, donde un grupo disfrazado como autoridades municipales, pomposamente descubría supuestas placas, haciéndose fotos con los supuestos periodistas. El nuevo talante de la corporación democrática se traduce en la presencia del nuevo teniente de alcalde, Manuel González, antiguo párroco de Belén y activista vecinal ${ }^{38}$, que asistió divertido a la representación ciudadana.

\footnotetext{
${ }^{38}$ ASOCIACIÓN DE VECINOS PILARICA, Pilarica. Un barrio de Valladolid con historia, Valladolid, Sever-Cuesta, 2007, p. 115.
} 


\section{Conclusiones}

En el presente artículo hemos glosado una serie de acciones satíricas llevadas a cabo por el movimiento vecinal de una ciudad media de la España del tardofranquismo y la Transición. Valladolid sufrió como pocas urbes del país los estragos del desarrollismo franquista; sus barriadas padecieron las carencias que explican y justifican una movilización equiparable en escala a la de ciudades de la entidad de Barcelona ${ }^{39}$ o Madrid 40 .

Frente a las tácticas llevadas a cabo por obreros y estudiantes para lograr mejoras en sus ámbitos y buscar la democratización del país, como pudiera ser la huelga, principal arma del movimiento obrero, los vecinos deberán idear otros métodos menos directos y contundentes no sólo para lograr sus objetivos de mejorar sus barrios y dignificar la vida urbana sino también para concitar el apoyo de la opinión pública y evitar en lo posible la represión de las autoridades. De esta forma, humor, parodia y reivindicación fueron de la mano en muchas de las luchas emprendidas por los barrios de Valladolid. Al fin y al cabo, la mayor parte de las acciones descritas fueron tan divertidas para la ciudadanía que las disfrutó como para sus participantes, lo que no obsta para señalar que por divertido que fuera un recital de canción protesta, la España de la Transición castigaba con dureza toda oposición de la calle. La sombra de la dictadura era aún alargada y la poca o mucha democracia de la que ahora disfrutamos, debió ser conquistada con tesón por un puñado de gente con una idea diferente de lo que debía ser el país.

\footnotetext{
${ }^{39}$ MOLINERO, Carme, YSÀS, Pere (coords.), Construint la ciutat democràtica. El moviment veïnal durant el tardofranquisme i la transició, Barcelona, Icària, 2010.

${ }^{40}$ CABRERIZO, Maite, Treinta... y tantos. La lucha del movimiento vecinal en Madrid, desde sus comienzos hasta hoy, Madrid, Vecinos de Madrid, 1998.
} 


\section{* El autor}

Constantino Gonzalo Morell se licenció en Historia en la Universidad de Valladolid (2005) y es Doctor en Historia por la misma Universidad desde 2011. Fue doctorando del Instituto Universitario de Historia Simancas y ha expuesto sus trabajos de investigación sobre el movimiento vecinal vallisoletano en múltiples congresos, conferencias y artículos.

En breve aparecerá su primer libro sobre la aportación a la democracia del movimiento asociativo vecinal de Valladolid.

URL: < http://studistorici.com/progett/autori/\#Morell >

\section{Per citare questo articolo:}

MORELL, Constantino Gonzalo, "Los barrios ríen de la ciudad. Las acciones satíricas del movimiento vecinal español. El caso de Valladolid, 1970-1986», Diacronie. Studi di Storia Contemporanea: La satira fa storia. Eventi, pratiche, linguaggi, 29/10/2012,

URL:< http://www.studistorici.com/2012/10/29/morell_numero_11/>

Diacronie Studi di Storia Contemporanea $\}$ www.diacronie.it

Risorsa digitale indipendente a carattere storiografico. Uscita trimestrale.

redazione.diacronie@hotmail.it

Comitato di redazione: Marco Abram - Giampaolo Amodei - Jacopo Bassi - Luca Bufarale - Gianluca Canè - Alessandro Cattunar - Alice De Rensis - Barbara Galimberti - Deborah Paci - Fausto Pietrancosta - Matteo Tomasoni - Luca Zuccolo

Diritti: gli articoli di Diacronie. Studi di Storia Contemporanea sono pubblicati sotto licenza Creative Commons 2.5 .

Possono essere riprodotti a patto di non modificarne i contenuti e di non usarli per fini commerciali. La citazione di

estratti è comunque sempre autorizzata, nei limiti previsti dalla legge. 